\title{
Cardiovascular magnetic resonance using T1-mapping, T2-weighted and late gadolinium enhancement imaging provides a high diagnostic yield in patients presenting with acute chest pain, positive troponin and non-obstructive coronary arteries
}

\author{
Vanessa M Ferreira ${ }^{1 *}$, Erica Dall'Armellina', Stefan K Piechnik ${ }^{1}$ Theodoros D Karamitsos ${ }^{1}$, Jane M Francis ${ }^{1}$, \\ Robin Choudhury ${ }^{1}$, Keith Channon ${ }^{1}$, Rajesh Kharbanda', Colin Forfar ${ }^{1}$, Oliver Ormerod ${ }^{1}$, Bernard D Prendergast ${ }^{1}$, \\ Attila Kardos ${ }^{2}$, Jim Newton ${ }^{1}$, Matthias G Friedrich ${ }^{3,4}$, Matthew D Robson', Stefan Neubauer ${ }^{1}$ \\ From 17th Annual SCMR Scientific Sessions \\ New Orleans, LA, USA. 16-19 January 2014
}

\section{Background}

Patients presenting with chest pain, raised troponin but non-obstructive coronary arteries pose a clinical challenge in diagnosis, prognosis and management. We hypothesized that early, multiparametric cardiovascular magnetic resonance (CMR) imaging can localize areas of injury and provide a diagnosis these cases.

\section{Methods}

We prospectively studied 120 patients (mean age $50 \pm$ 17 yrs; $50 \%$ female) presenting with chest pain, positive troponin I (normal $<0.04$, median 3.99, range 0.07 to $>60$ $\mu \mathrm{g} / \mathrm{L}$ ) and non-obstructive coronaries. Early CMR at $1.5 \mathrm{~T}$ (median 3 days, IQR 1-6 days) included cine, dark-blood T2-weighted (STIR), native T1-mapping (ShMOLLI) and late gadolinium enhancement (LGE) imaging (Figure 1). Findings were compared to 50 controls. Image analysis included: the detection of edema comparing T2 signal intensity of myocardium to skeletal muscle $(>2.0)$ or remote myocardium $(>2 \mathrm{SD})$; myocardial $\mathrm{T} 1$ times (areas of injury with an area of $\geq 40 \mathrm{~mm} 2$ with $\mathrm{T} 1>990 \mathrm{~ms}$ ); and presence of LGE.

'Division of Cardiovascular Medicine, Radcliffe Department of Medicine, University of Oxford, Oxford, UK

Full list of author information is available at the end of the article

\section{Results}

Using only conventional CMR techniques (cine, T2W and LGE; Figure 2), there was a high diagnostic yield of $95 \%$. Edema was detected in $79 \%$ and LGE in $61 \%$ of patients. Based on CMR findings including the type, pattern and regional distribution of injury, the commonest diagnosis was myocarditis (37\%), followed by Takotsubo cardiomyopathy (23\%), myocardial infarction (18\%), acute regional stunning (9\%; wall motion abnormality with edema but no LGE), dilated cardiomyopathy (4\%), hypertrophic cardiomyopathy (3\%), and missed pulmonary embolism (1\%). In 11/21 (52\%) of patients with MI, a patent foramen ovale (PFO) was demonstrated on echocardiography with agitated saline contrast, suggesting these patients may have suffered a paradoxical coronary embolism. The remaining $5.0 \%(\mathrm{n}=6)$ of patients had no findings on T2W and LGE imaging. However, native T1-mapping identified areas of injury (T1 >990 $\mathrm{ms})$ in 4 out of the remaining 6 patients, improving the detection rate to $98 \%$.

\section{Conclusions}

Using conventional T2W and LGE techniques, early CMR has a high diagnostic yield (95\%) in patients presenting with troponin-positive chest pain but nonobstructive coronary arteries. Native T1-mapping 


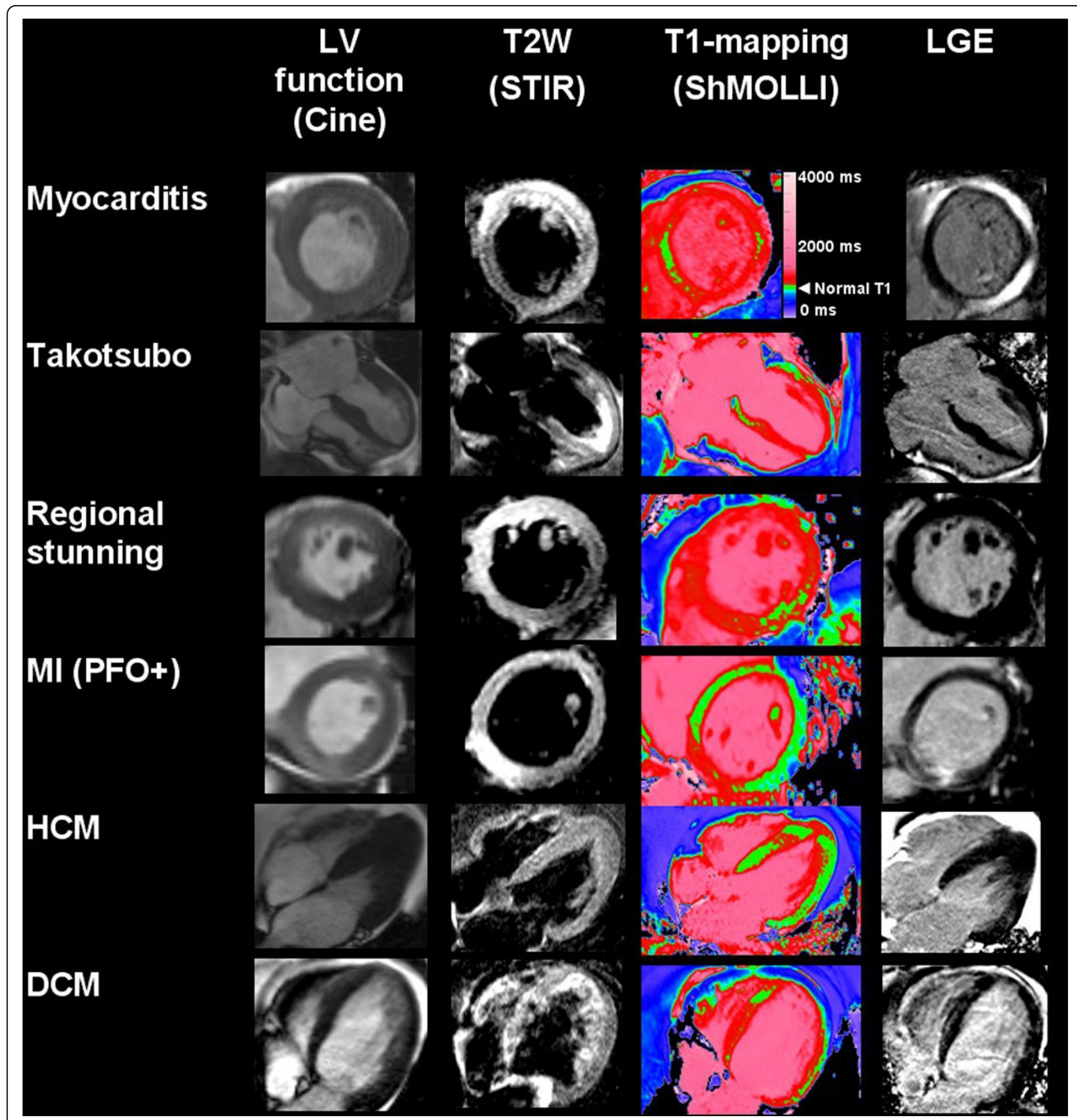

Figure 1 Early CMR using multiparametric tissue characterization including cine, T2-weighted (T2W), T1-mapping and late gadolinium enhancement imaging to assess patients presenting with acute chest pain, positive troponins and non-obstructive coronary arteries. On T1-maps, green areas within the LV denote normal myocardium; red areas have a T1> 990 ms, consistent with acute injury.

detected additional areas of abnormality when conventional CMR was "normal", improving the detection rate to $98 \%$. Early multiparametric CMR is able to localize areas of affected myocardium and may aid in the further management or diagnostic workup in this patient cohort.

\section{Funding}

This study is funded by the Oxford National Institute for Health Research Biomedical Research Centre Programme. VMF received funding from the Alberta Innovates Health Solutions (AIHS) Clinical Fellowship and the University of Oxford Clarendon Fund Scholarship. 


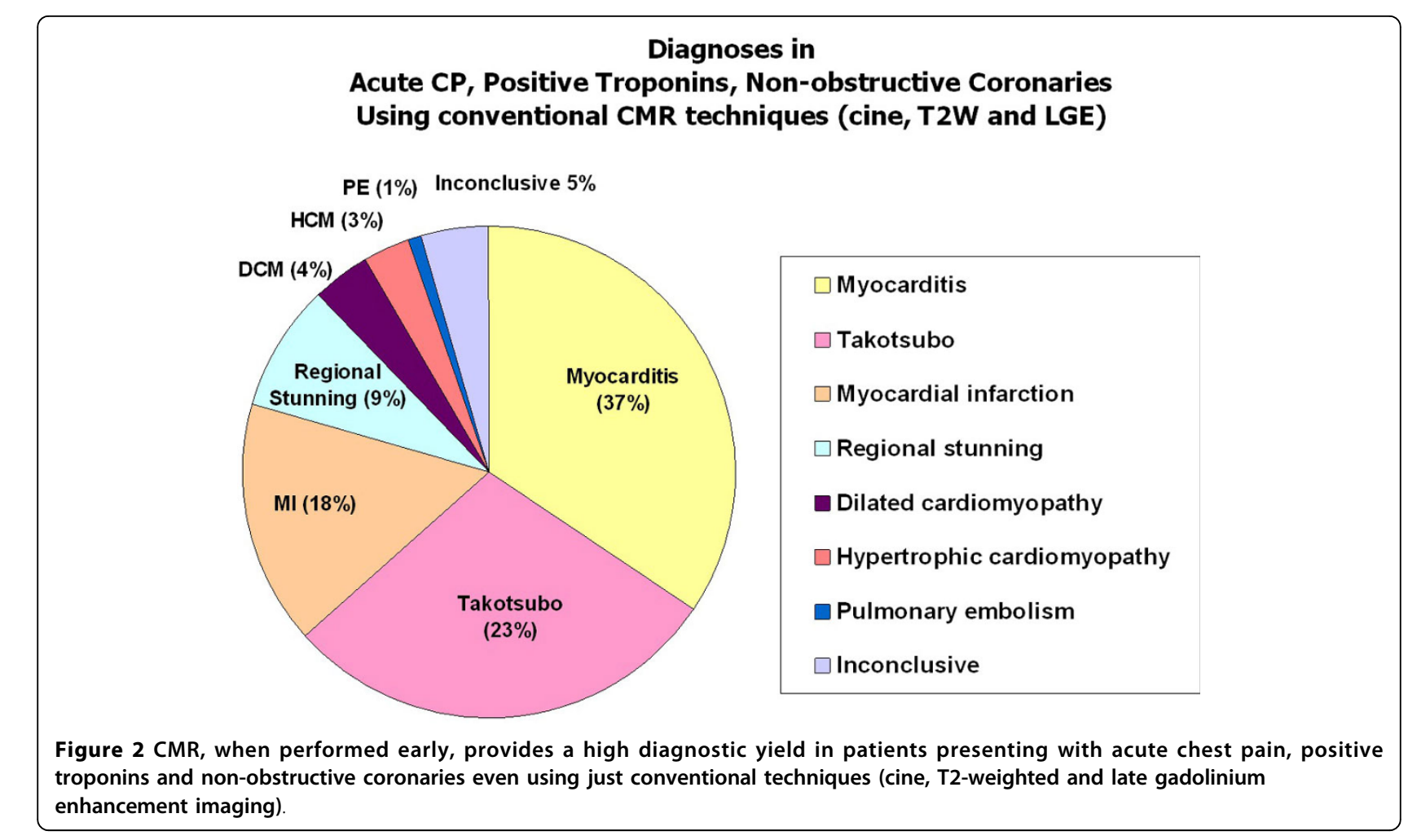

$\mathrm{RC}$ is a Wellcome Trust Senior Research Fellow in Clinical Science. SN and RC acknowledge support from the British Heart Foundation Centre of Research Excellence, Oxford.

\section{Authors' details}

'Division of Cardiovascular Medicine, Radcliffe Department of Medicine, University of Oxford, Oxford, UK. ${ }^{2}$ Department of Cardiology, Milton Keynes NHS Hospital Foundation trust, Milton Keynes, UK. ${ }^{3}$ Department of Cardiology, Université de Montréal, Montréal, Quebec, Canada. ${ }^{4}$ Stephenson Cardiovascular MR Centre, Libin Cardiovascular Institute of Alberta, University of Calgary, Calgary, Alberta, Canada.

Published: 16 January 2014
Cite this article as: Ferreira et al.: Cardiovascular magnetic resonance using T1-mapping, T2-weighted and late gadolinium enhancement imaging provides a high diagnostic yield in patients presenting with acute chest pain, positive troponin and non-obstructive coronary arteries. Journal of Cardiovascular Magnetic Resonance 2014 16(Suppl 1): P215.
Submit your next manuscript to BioMed Central and take full advantage of:

- Convenient online submission

- Thorough peer review

- No space constraints or color figure charges

- Immediate publication on acceptance

- Inclusion in PubMed, CAS, Scopus and Google Scholar

- Research which is freely available for redistribution 